\title{
Mitogen-activated protein kinase mediates the apoptosis of highly metastatic human non-small cell lung cancer cells induced by isothiocyanates
}

\author{
Huiqin Yan $^{1} \dagger$, Yu Zhu ${ }^{1} \dagger$, Boning Liu ${ }^{1}$, Heng Wu ${ }^{1}$, Yongwen $\mathrm{Li}^{1}$, Xiang $\mathrm{Wu}^{2}$, Qinghua Zhou ${ }^{1 *}$ \\ and $\mathrm{Ke} \mathrm{Xu}^{1 *}$ \\ ${ }^{1}$ Tianjin Key Laboratory of Lung Cancer Metastasis and Tumor Microenvironment, Tianjin Lung Cancer Institute, Tianjin \\ Medical University General Hospital, Tianjin 300052, China \\ ${ }^{2}$ Core Facility Center, Tianjin Medical University General Hospital, Tianjin 300052, China
}

(Received 10 December 2010 - Revised 28 February 2011 - Accepted 17 March 2011 - First published online 23 June 2011)

\section{Abstract}

Dietary isothiocyanates have been shown to possess anti-tumour activity, inhibiting several types of cultured human cancer cell growth. However, there are limited studies on their effects on cancer cell metastasis. Our previous study showed that benzyl isothiocyanate (BITC) and phenethyl isothiocyanate (PEITC) suppressed human lung cancer cell metastasis potential. In the present study, we found BITC $(7.5$ and $10 \mu \mathrm{M})$ and PEITC $(12.5$ and $20 \mu \mathrm{M})$ induced highly metastatic human non-small cell lung cancer L9981 cell apoptosis in a dose-dependent manner. Caspase- 3 was activated. They also caused cell cycle arrest at the $\mathrm{G}_{2} / \mathrm{M}$ phase, via modulation of cyclin $\mathrm{B} 1$ expression. The mitogen-activated protein kinase (MAPK) signalling pathway was involved. c-Jun N-terminal kinase, extracellular signal-regulated protein kinase $1 / 2$ and p38 were activated in a dose-dependent manner; activator protein 1 (AP-1) transcriptional activation and cyclin D1 expression were repressed. Apoptosis and MAPK activation were abrogated by anti-oxidant $N$-acetyl cysteine (NAC), suggesting that cell death signalling was triggered by oxidative stress. Further microarray analysis evaluated the potential targeted genes related to apoptosis and the cell cycle. Our studies suggested that BITC and PEITC suppressed the metastasis potential of highly metastatic lung cancer cells by inducing apoptosis and cell cycle arrest, via targeting the MAPK/AP-1 pathway. This may provide a novel approach for metastasis therapy of lung cancer by dietary isothiocyanates and possibly other types of cancer.

\section{Key words: Lung cancer: Isothiocyanates: Mitogen-activated protein kinase: Apoptosis: Cell cycle}

Lung cancer is the most common cause of death in men and second only to breast cancer in women. It is responsible for 1.38 million deaths annually ${ }^{(1)}$. Non-small cell lung cancer (NSCLC) accounts for approximately $80-85 \%$ of all cases of lung cancer. About $40 \%$ of patients with NSCLC present at an advanced stage, with metastatic or locally advanced disease, which underscores the importance of identifying therapeutic schemes that may benefit this large patient population. Combination chemotherapy, usually platinum-based, is currently the first-line therapy of choice; however, the prognosis for patients with advanced NSCLC remains poor with a median survival time of $8-11$ months, a 1-year survival rate of $30-45 \%$, and a 5 -year survival rate $<5 \%{ }^{(2,3)}$. The treatment of NSCLC is therefore a major unmet need, and development of novel anti-cancer drugs is urgently needed.
Cruciferous vegetables have been widely accepted as potential diet components that may decrease the risk of cancer ${ }^{(4)}$. Isothiocyanates are abundant in cruciferous vegetables such as broccoli, watercress and Brussels sprouts. They have recently been of intense interest for their anti-carcinogenic activities and potential use in the chemoprevention of cancer. Chemopreventive activity is thought to be associated with the inhibition of the metabolic activation of carcinogens by phase I enzymes, cytochrome $\mathrm{P} 450$ isozymes and increased excretion of carcinogens by inducing increased activities of phase II enzymes, quinone reductase and GSH S-transferases ${ }^{(5)}$. A further feature of the pharmacological activity of isothiocyanates such as phenethyl isothiocyanate (PEITC), benzyl isothiocyanate (BITC) and sulforaphane is their anti-cancer activity. They inhibit several types of cancer cell growth, such as

Abbreviations: AP1, activator protein 1; BITC, benzyl isothiocyanate; JNK, c-Jun N-terminal kinase; MAPK, mitogen-activated protein kinase; NAC, $N$-acetyl cysteine; NSCLC, non-small cell lung cancer; PEITC, phenethyl isothiocyanate; ROS, reactive oxygen species.

*Corresponding authors: Professor K. Xu, fax +86 22 60363013, email ke_xu@hotmail.com; Professor Q. H. Zhou, fax +86 22 60363013, email zhouqh1016@yahoo.com.cn

†These authors contributed equally to this work. 
(a)<smiles>O=S(=O)(NCc1ccccc1S)c1ccccc1</smiles>

(b)<smiles>CS(=O)(=O)NCCc1ccccc1</smiles>

Fig. 1. Structures of (a) benzyl isothiocyanate and (b) phenethyl isothiocyanate.

leukaemia $^{(6,7)}$, prostate cancer $^{(8)}$, breast cancer $^{(9)}$, lung cancer $^{(10)}$, cervical cancer ${ }^{(11)}$, colorectal cancer ${ }^{(12)}$, etc.

Recent studies have revealed that isothiocyanates have anti-angiogenic and anti-metastatic effects. Isothiocyanates inhibited tumour-specific angiogenesis by down-regulating nitric oxide, TNF- $\alpha$ and proinflammatory cytokine production, and by the inactivation of $\mathrm{Akt}^{(13-15)}$. Isothiocyanates also suppressed the metastasis potential of human hepatoma cells $^{(16)}$, colon cancer cells ${ }^{(17)}$ and breast cancer cells ${ }^{(18)}$. These effects are mediated by decreasing the expression of matrix metalloproteinases, proinflammatory cytokines, growth factors such as vascular endothelial growth factor, transcription factor twist, and by increasing the expression of tissue inhibitors of matrix metalloproteinase. In our previous study, by using a highly metastatic human large cell lung cancer cell line L9981, we showed that BITC and PEITC suppressed the metastasis potential of NSCLC by the modulation of metastasis-related gene expression, inhibition of Akt/NF-kB pathway and induction of oxidative stress ${ }^{(19)}$.

In the present study, we further investigate the effect of BITC and PEITC (Fig. 1) on highly metastatic L9981 cell growth, including the induction of apoptosis and cell cycle arrest and regulation of the mitogen-activated protein kinase (MAPK) signalling pathway. Moreover, to explore potential molecular targets, we examined their effects on global gene expression profile.

\section{Materials and methods}

\section{Materials}

PEITC, BITC, $N$-acetyl cysteine (NAC), RNase A and propidium iodide were purchased from Sigma-Aldrich Inc. (St Louis, MO, USA). Mouse monoclonal antibodies against cyclin D1, cyclin $\mathrm{B} 1$ and rabbit polyclonal antibodies against $\mathrm{p}-\mathrm{c}$-jun $\mathrm{N}$-terminal kinase (JNK), p-p38, p-extracellular signal-regulated protein kinase (ERK1/2) were purchased from Cell Signaling (Beverly, MA, USA); mouse monoclonal antibody against $\beta$-actin was purchased from Sigma; secondary antibodies coupled to HRP were purchased from ZSGB-BIO (Beijing, China). TRIzol was purchased from Invitrogen (Carlsbad, CA, USA); reverse transcription and real-time PCR kits were purchased from TaKaRa Biotechnology Company (Dalian, China). An RNeasy kit was purchased from Qiagen (Valencia, CA, USA). Microarray GeneChips were purchased from Affymetrix, Inc. (Santa Clara, CA, USA). pAP-1-luc was purchased from Clontech (Mountain View, CA, USA); pRL-SV40 was purchased from Promega (Madison, WI, USA)

\section{Cell culture}

The highly metastatic human lung cancer cell line L9981 was established from a human lung large cell carcinoma cell line $\left(\right.$ WCQH29801) ${ }^{(20)}$. Cells were grown and maintained in the RPMI-1640 medium supplemented with 10\% fetal bovine serum, $2 \mathrm{~mm}$-glutamine (GIBCO BRL, Grand Island, NY, USA) at $37^{\circ} \mathrm{C}$ and $5 \% \mathrm{CO}_{2}$. Penicillin and streptomycin were not added into the culture medium to avoid any cross-effect with isothiocyanates.

\section{Apoptosis assay}

The cells were incubated with PEITC or BITC for the indicated times. The percentage of cells undergoing apoptosis was determined by an Annexin V-FITC Apoptosis Detection kit (BD Biosciences, San Jose, CA, USA), following the manufacturer's instructions. Briefly, cells were washed with PBS and re-suspended in a $1 \times$ binding buffer at a concentration of $1 \times 10^{6} \mathrm{cell} / \mathrm{ml}$. Annexin V-FITC and propidium iodide were added to cells and incubated for $15 \mathrm{~min}$ at room temperature in the dark. Then $1 \times$ binding buffer was added and analysed

Table 1. Real-time PCR primer sequences

\begin{tabular}{lllc}
\hline Primers & & Sequence $\left(5^{\prime}-3^{\prime}\right)$ & Length of amplicons $(\mathrm{bp})$ \\
\hline PDCD4 & Forward & GTTGGCAGTATCCTTAGCATTGG & 105 \\
& Reverse & TCCACATCAGTTGTGCTCATTAC & 77 \\
CCNG2 & Forward & TCTCGGGTTGTTGACGTCTA & 145 \\
& Reverse & CCTCAATCAAACTCAGCCCTT & 71 \\
GADD45A & Forward & GAGAGCAGAAGACCGAAAGGA & 7 \\
& Reverse & CACAACACCACGTTATCGGG & \\
GAPDH & Forward & CCACCCATGGCAAATTCC & \\
& Reverse & GATGGGATTTCCATTGATGACA & \\
\hline
\end{tabular}

$P D C D 4$, programmed cell death 4; CCNG2, cyclin G2; GADD45A, growth arrest and DNA damage-inducible $\alpha$; GAPDH, glyceraldehyde-3-phoshate dehydrogenase. 
on a FACSAria flow cytometer (Becton Dickenson, San Jose, CA, USA).

\section{Cell cycle analysis}

Cell cycle analysis was performed as described previously ${ }^{(7)}$. Briefly, L9981 cells were incubated with PEITC or BITC for $24 \mathrm{~h}$, sedimented by centrifugation $(300 \mathrm{~g}, 5 \mathrm{~min})$, washed with PBS, and the cell pellet was fixed by the addition of $70 \%$ ethanol. The fixed cells were stored in the dark at $4^{\circ} \mathrm{C}$ overnight. The cell pellets were re-suspended in PBS, with $1 \mathrm{mg} / \mathrm{ml}$ of RNase A for $30 \mathrm{~min}$ at $37^{\circ} \mathrm{C}$. The cells were then
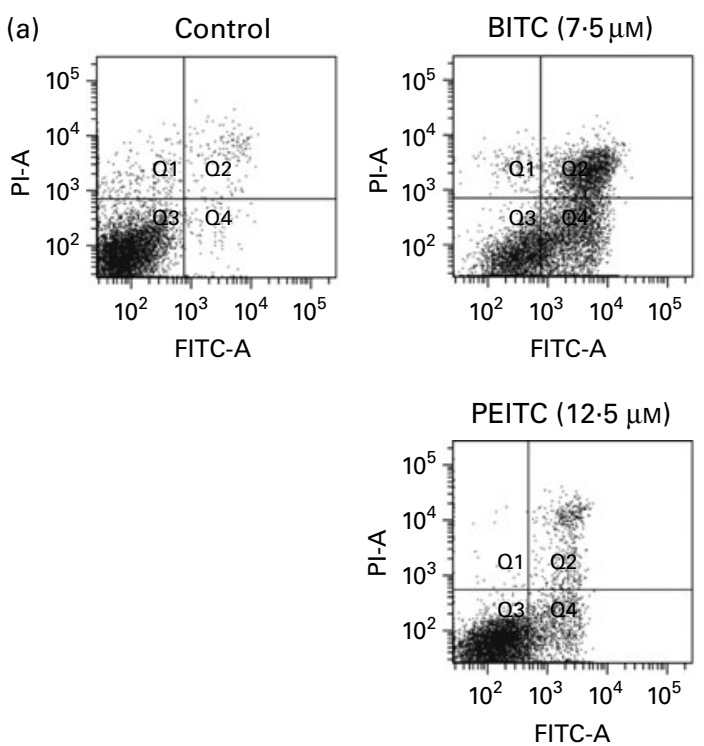

(b)

BITC

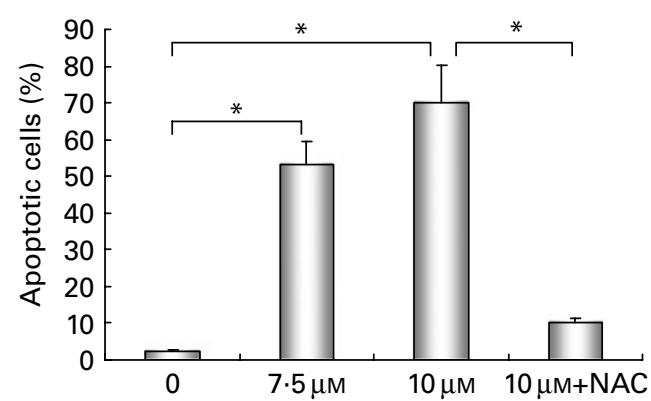

collected by centrifugation and re-suspended in $100 \mu \mathrm{m}$-propidium iodide in $0 \cdot 1 \%$ sodium citrate with $0 \cdot 1 \%$ Triton $\mathrm{X}-100$ and transferred to a flow cytometric analysis tube. Flow cytometric analysis was performed on a FACSAria flow cytometer (Becton Dickenson). Data were analysed by ModFit LT software (Verity Software House, Topsham, ME, USA).

\section{Western blotting analysis}

Western blotting was performed as described previously ${ }^{(19)}$. Briefly, L9981 cells were incubated with PEITC or BITC for $24 \mathrm{~h}$, washed with PBS, and the cell pellets were prepared
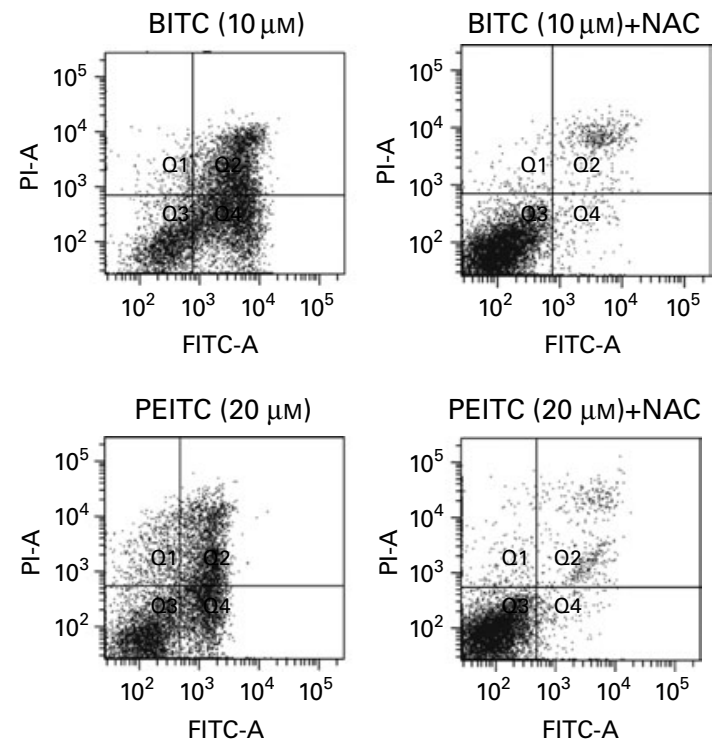

PEITC $(20 \mu \mathrm{M})+\mathrm{NAC}$

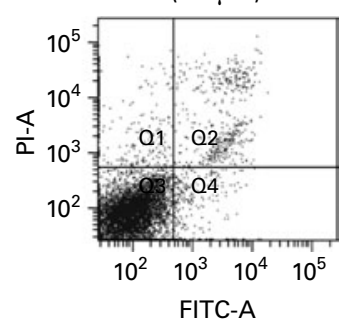

(c)

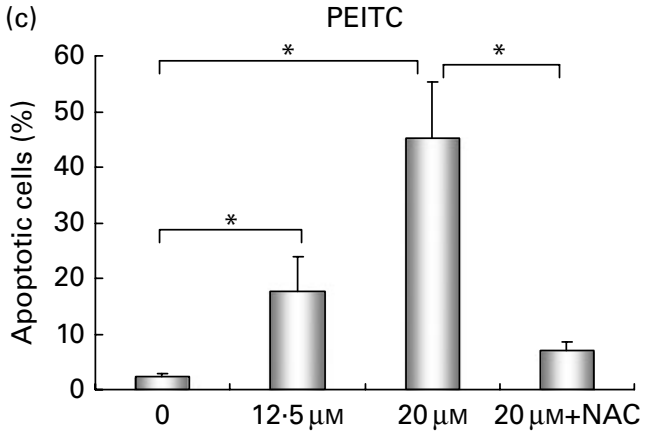

(d)

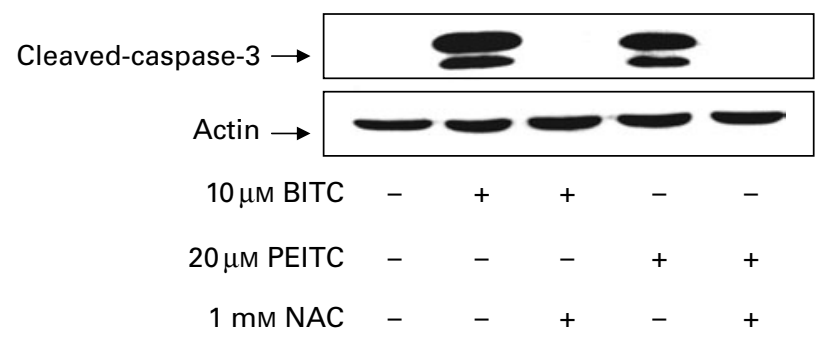

Fig. 2. Induction of apoptosis by benzyl isothiocyanate (BITC) and phenethyl isothiocyanate (PEITC). L9981 cells were treated with 7.5-20 $\mu \mathrm{M}$ of BITC or PEITC for $24 \mathrm{~h}$. For $N$-acetyl cysteine (NAC) protection, cells were pretreated with NAC $(1 \mathrm{mM})$ for $1 \mathrm{~h}$. (a) Dose-response of induction of apoptosis was determined by flow cytometry after Annexin V-FITC/propidium iodide staining. (b) The percentage of apoptotic cells induced by BITC. (c) The percentage of apoptotic cells induced by PEITC. (d) Caspase-3 activities determined by Western blotting. The samples were harvested, then lysed and subjected to SDS-PAGE, transferred to the membrane and blotted with the antibody against cleaved caspase-3. Values are means, with standard deviations of three independent experiments represented by vertical bars. ${ }^{*}$ Mean values were significantly different $(P<0.001)$. Similar results were obtained in three independent experiments. 
in lysis buffer (20 mm-Tris (pH 7.5), $150 \mathrm{mm-NaCl,} 1 \%$ Triton $\mathrm{X}-100$, sodium pyrophosphate, $\beta$-glycerophosphate, EDTA, $\mathrm{Na}_{3} \mathrm{VO}_{4}$, leupeptin). Lysates were electrophoresed on SDS-PAGE and transferred to nitrocellulose membranes. The membranes were blocked for $1 \mathrm{~h}$ at room temperature with 5\% milk protein, $0 \cdot 1 \%$ Tween 20 in PBS, and then were probed with mouse anti-cyclin B1, cyclin D1 or rabbit anti-p-JNK, p-p38, p-ERK1/2 antibodies at 1:1000 dilution in $0 \cdot 1 \%$ Tween 20 in PBS with $5 \%$ BSA overnight at $4^{\circ} \mathrm{C}$. After washing, the membranes were probed with HRP-conjugated secondary antibodies at 1:5000 dilution in 0.1\% Tween 20 in PBS with $3 \%$ milk protein for $1 \mathrm{~h}$. The blots were developed with the Phototope HRP Western Blot Detection System (Cell Signaling).

\section{DNA transfection}

Transfection of L9981 cells was carried out using Lipofectamine 2000 (Invitrogen), following the manufacturer's instructions. Briefly, L9981 cells were plated in a twenty-four-well plate at $1 \times 10^{5}$ cells/well. The cells were co-transfected with $400 \mathrm{ng}$ of pAP-1-luc, and $4 \mathrm{ng}$ of pRL-SV40 served as an internal control. The cells were rested for $8 \mathrm{~h}$ after transfection and were then incubated with BITC or PEITC for $18 \mathrm{~h}$. Luciferase assays were performed using the Dual-luciferase Reporter (a)

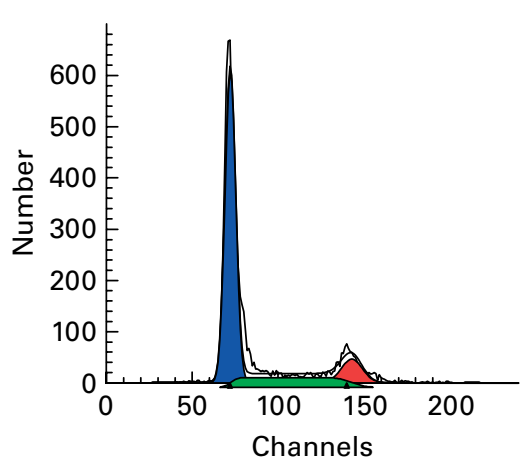

(FL3-FL3 fluorescence)

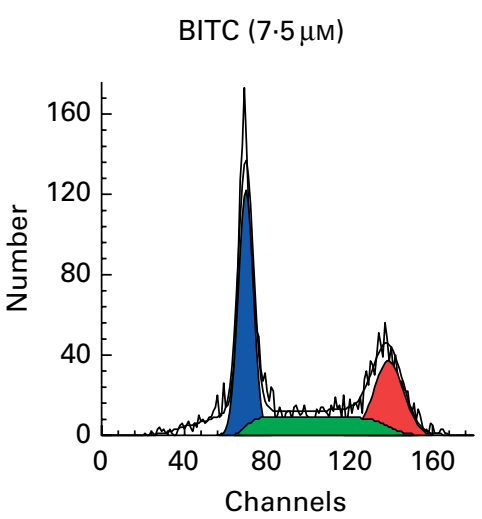

(FL3-FL3 fluorescence)

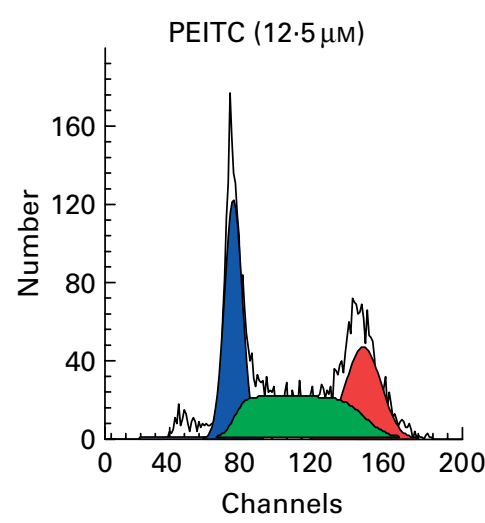

(FL3-FL3 fluorescence)
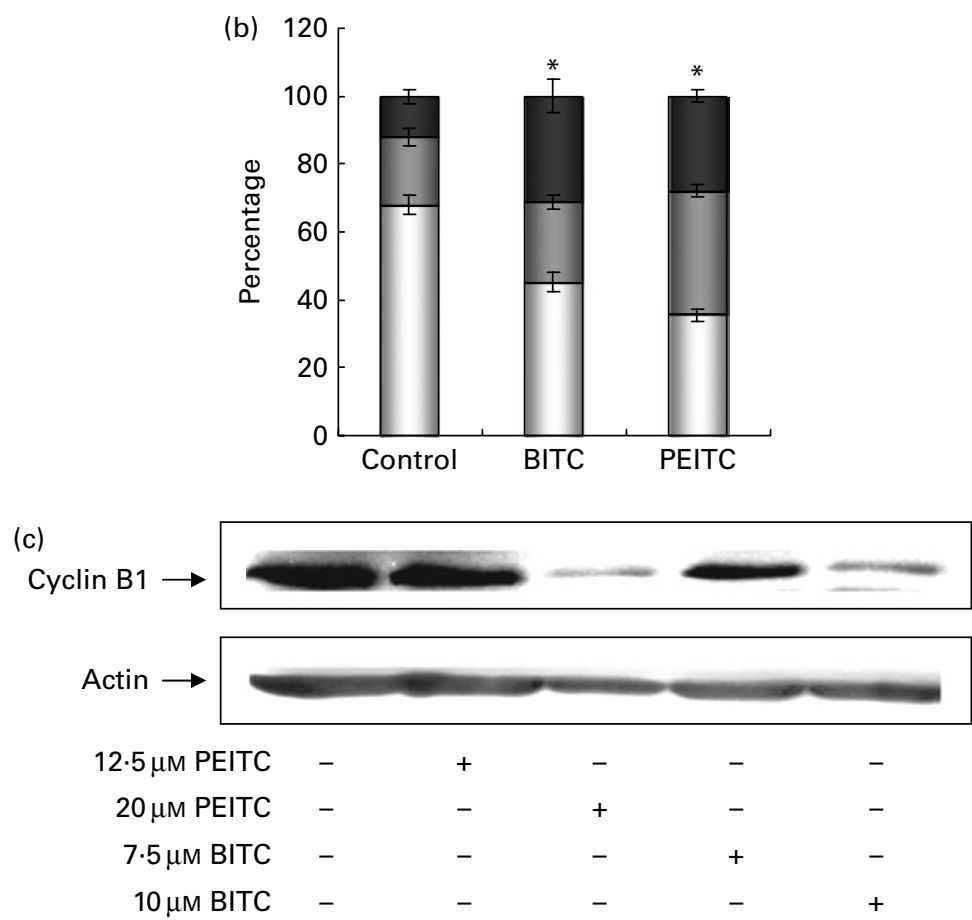

Fig. 3. Effect of benzyl isothiocyanate (BITC) and phenethyl isothiocyanate (PEITC) on cell cycle. L9981 cells were treated with $7.5 \mu \mathrm{M}$ of BITC or $12.5 \mu \mathrm{M}$ of PEITC for $24 \mathrm{~h}$. (a) DNA content was determined by flow cytometry after fixation with ethanol and staining the cells with propidium iodide $\square$, G0/G1; $\square, \mathrm{S}$; $\square$, G2/M. (b) The percentage of cell cycle phases ( $\mathrm{G}, \mathrm{G} 2 / \mathrm{M}$; $\mathrm{G}, \mathrm{S}$; $\square, \mathrm{G} 0 / \mathrm{G} 1$ ) was analysed by ModFit LT software. (c) Cyclin B1 expression level was determined by Western blotting. The samples were harvested, then lysed and subjected to SDS-PAGE, transferred to a membrane and blotted with the antibody against cyclin B1. Values are means, with standard deviations of three independent experiments represented by vertical bars. ${ }^{*}$ Mean values were significantly different $(P<0.01)$. Similar results were obtained in three independent experiments. 
Assay System (Promega) following the manufacturer's instructions, on a BERTHOLD TriStar LB 941 microplate reader (Berthold Technologies, Bad Wildbad, Germany).

\section{Reverse transcription}

Total RNA was extracted from the cells using TRIzol (Invitrogen). Reverse transcription was performed as described previously ${ }^{(21)}$ using the TaKaRa reverse transcription kit following the manufacturer's instructions, on a DNAEngine Peltier Thermal Cycler (Bio-Rad, Richmond, CA, USA). Briefly, RNA and random primers were denatured for $10 \mathrm{~min}$ at $70^{\circ} \mathrm{C}$; then M-MLV reverse transcriptase, deoxynucleotide triphosphates, RNase inhibitor and reverse transcription buffer were added and incubated for $10 \mathrm{~min}$ at $30^{\circ} \mathrm{C}$, $60 \mathrm{~min}$ at $42^{\circ} \mathrm{C}$ and $15 \mathrm{~min}$ at $70^{\circ} \mathrm{C}$.

\section{Real-time quantitative $P C R$}

The primers were synthesised by SBS Genetech Company (Beijing, China). mRNA levels were detected by SYBR Green-based real-time PCR. PCR were performed as described previously $^{(21)}$. Briefly, PCR were performed in the following conditions: $10 \mathrm{~s}$ at $95^{\circ} \mathrm{C}$, then forty cycles at $95^{\circ} \mathrm{C}$ for $5 \mathrm{~s}$ and $65^{\circ} \mathrm{C}$ for $34 \mathrm{~s}$ on an ABI Prism 7500 Sequence Detector System (Applied Biosystems, Foster City, CA, USA). The primers for the detected genes are listed in Table 1.

\section{Microarray analysis}

L9981 cells were incubated with BITC for $24 \mathrm{~h}$. Total RNA was extracted from the cells using an RNeasy kit (Qiagen), following the manufacturer's instructions. The quality of each RNA sample was determined on an Experion Automated Electrophoresis Station (Bio-Rad). Gene expression profiles were analysed by microarray experiments, using Affymetrix GeneChip Human Genome U133 Plus 2.0 (Affymetrix, Inc.), which contains more than 47000 transcripts and variants. The targets were prepared according to Affymetrix Gene Chip $3^{\prime}$ IVT Express Kit protocol. Briefly, First-Strand cDNA was synthesised by reverse transcription and then SecondStrand cDNA was synthesised. The biotin-modified aRNA was synthesised by in vitro transcription and fragmented. Then the targets were hybridised to the GeneChip Human Genome U133 plus 2.0 Array.

\section{Microarray data analysis}

Raw data were acquired and later analysed using Affymetrix GeneChip Operating Software (GCOS) 1.4, scaled to a default target signal value of 500. Absolute and comparative analysis was performed using the Affymetrix MAS 5.0 algorithm in GCOS 1.4. Probe sets with increase/decrease calls, signal log ratio higher than 1 or lower than -1 and change in $P$ value lower than 0.05 were defined as significant probe sets and selected for further analysis. Additionally, calls of probe sets with higher signal values and with a detection $P$ value lower than 0.05 must be present for single chip analysis. Annotations were analysed using a combination of interactive query at NetAffx (www.affymetrix.com) and R suite (annaffy package from the Bioconductor suite). Clustering analysis was done using MultiExperiment Viewer (MeV) 4.5.1 ( J. Craig Venter Institute, Rockville, MD, USA; www.tigr.org). Hierarchical clustering analysis was done using Euclidean distance and average linkage clustering.

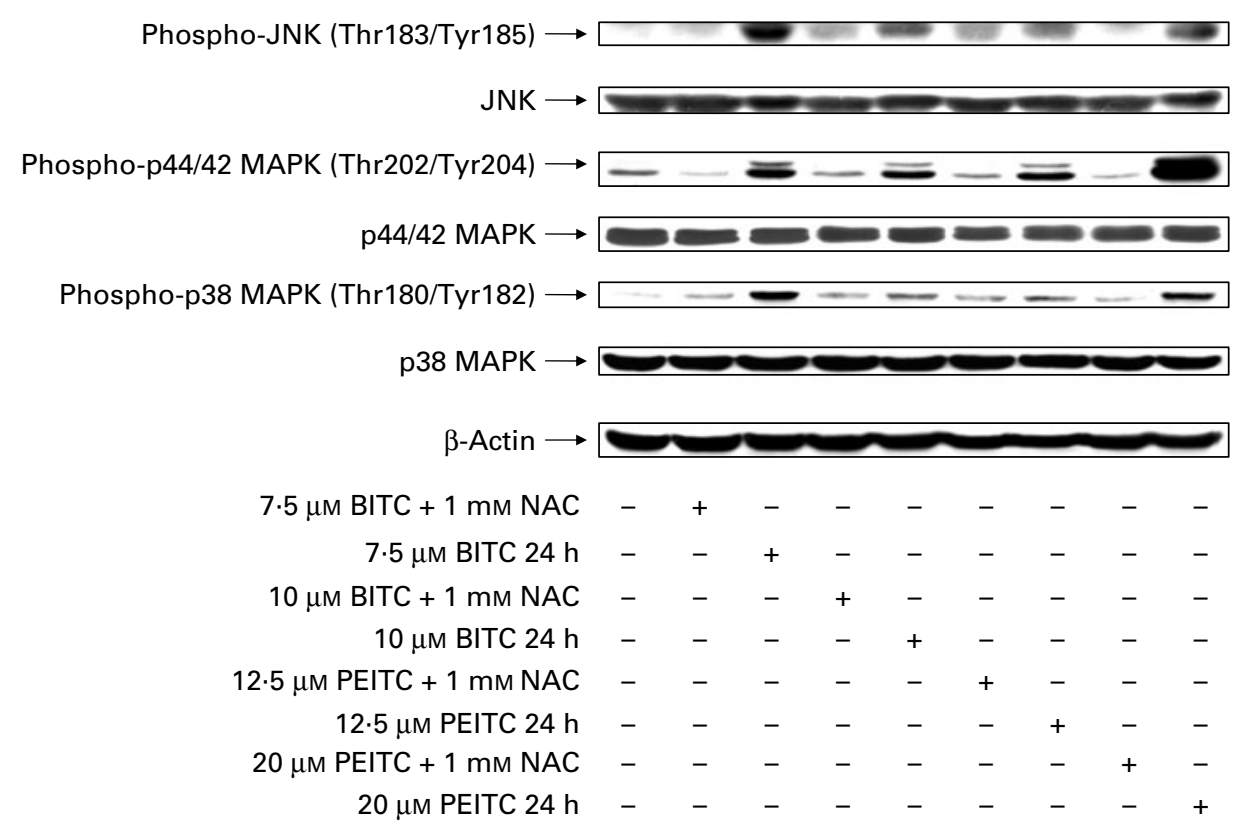

Fig. 4. Effect of isothiocyanates on mitogen-activated protein kinase (MAPK) phosphorylation. L9981 cells were treated with 7.5-20 $\mu \mathrm{M}$ of benzyl isothiocyanate (BITC) or phenethyl isothiocyanate (PEITC) for $24 \mathrm{~h}$. For $\mathrm{N}$-acetyl cysteine (NAC) protection, cells were pretreated with NAC (1 mM) for $1 \mathrm{~h}$. Samples were harvested, then lysed and subjected to SDS-PAGE, transferred to membrane and blotted with the antibodies against phospho-c-Jun N-terminal kinase ( $p$-JNK), phospho-extracellular signal-regulated protein kinase (p-ERK1/2) and phospho-p38. Similar results were obtained in three independent experiments. 


\section{Statistical analysis}

Data are presented as means and standard deviations. Variance analysis between groups was performed by one-way ANOVA, and significance of difference between control and treatment groups was analysed using Dunnett's multiple comparison test. The differences with $P$ values $<0.05$ were considered statistically significant.

\section{Results}

\section{Benzyl isothiocyanate and phenethyl isothiocyanate induced apoptosis}

Our previous study showed that both BITC and PEITC inhibited L9981 cell growth in a dose-dependent manner, and $\mathrm{IC}_{50}$ values were 5.0 and $9.7 \mu \mathrm{M}$, respectively ${ }^{(19)}$. In the present study, we found that BITC and PEITC induced L9981 cell apoptosis in a dose-dependent manner (Fig. 2(a)). After $24 \mathrm{~h}$ treatment, 53.1 and $70.0 \%$ cells were apoptotic when treated with 7.5 and $10 \mu \mathrm{M}$ of BITC $(P<0.001)$, respectively; and $17 \cdot 7 \%$ and $45 \cdot 1 \%$ cells were apoptotic when treated with 12.5 and $20 \mu \mathrm{M}$ of PEITC $(P<0.001)$, respectively (Fig. 2(b) and (c)).

Numerous studies showed that isothiocyanates could induce reactive oxygen species (ROS) generation and caused oxidative stress. Our previous study also showed that BITC and PEITC elevated ROS level in L9981 cells ${ }^{(19)}$. Therefore, we investigated whether antioxidant NAC could protect cells from apoptosis. The cells were pretreated with $1 \mathrm{~mm}$ of NAC for $1 \mathrm{~h}$ before incubation with isothiocyanates. Flow cytometric analysis showed that apoptosis induced by both BITC and PEITC was effectively blocked $(P<0 \cdot 001$; Fig. 2(a)). Caspase- 3 is an effector caspase, triggering the apoptotic process. We evaluated the role of caspase- 3 in the apoptosis induction by isothiocyanates. The cells were treated with $10 \mu \mathrm{M}$ of BITC or $20 \mu \mathrm{m}$ of PEITC for $24 \mathrm{~h}$, and the activation of caspase-3 was detected by Western blotting. Fig. 2(d) shows that caspase- 3 was activated by both BITC and PEITC. Furthermore, pretreatment of cells with antioxidant NAC (1 mm) for $1 \mathrm{~h}$ abolished caspase-3 activation. This was consistent with our apoptosis analysis.

\section{Benzyl isothiocyanate and phenethyl isothiocyanate- induced cell cycle arrest}

Since the induction of apoptosis could not fully explain the reduction of cell growth, we determined whether BITC and PEITC lead to cell cycle arrest. The cells were treated with $7.5 \mu \mathrm{M}$ of BITC or $12.5 \mu \mathrm{M}$ of PEITC for $24 \mathrm{~h}$, and the cell cycles were analysed by flow cytometry. Both BITC and PEITC significantly arrested cell cycle progression (Fig. 3(a)). Flow cytometric analysis showed that BITC reduced the $\mathrm{G}_{0} / \mathrm{G}_{1}$ phase from 68.0 to $45.1 \%$ and increased $\mathrm{G}_{2} / \mathrm{M}$ phase from 11.9 to $31.2 \%(P<0.01)$; however, $\mathrm{S}$ phase was not affected, whereas PEITC reduced $\mathrm{G}_{0} / \mathrm{G}_{1}$ phase from 68.0 to $35.6 \%$ and increased both $\mathrm{S}$ and $\mathrm{G}_{2} / \mathrm{M}$ phases, from $20 \cdot 1$ to $36.5 \%$ and $11.9 \%$ to $27.9 \%(P<0.01)$, respectively (Fig. 3(b)). These results demonstrated that BITC and PEITC arrested
L9981 cell cycle progression; the cell cycles were arrested at the $\mathrm{G}_{2} / \mathrm{M}$ phase.

To investigate whether cell cycle arrest at the $G_{2} / M$ phase was mediated by cyclins, we examined the effects of isothiocyanates on cyclin expression. The cdc2-cyclin B1 kinase activity is pivotal in regulating the $\mathrm{G}_{2} / \mathrm{M}$ transition; therefore, we detected cyclin B1 protein expression level by Western blotting. Our data showed that cyclin B1 expression was reduced by BITC and PEITC in a dose-dependent manner (Fig. 3(c)). This suggested that cyclin B1 down-regulation may play a role in isothiocyanate induced $\mathrm{G}_{2} / \mathrm{M}$ phase arrest.

\section{Benzyl isothiocyanate and phenethyl isothiocyanate induced phosphorylation of mitogen-activated protein kinases}

There are a few signalling pathways involved in the induction of apoptosis; one of them is the MAPK pathway. MAPK

(a)

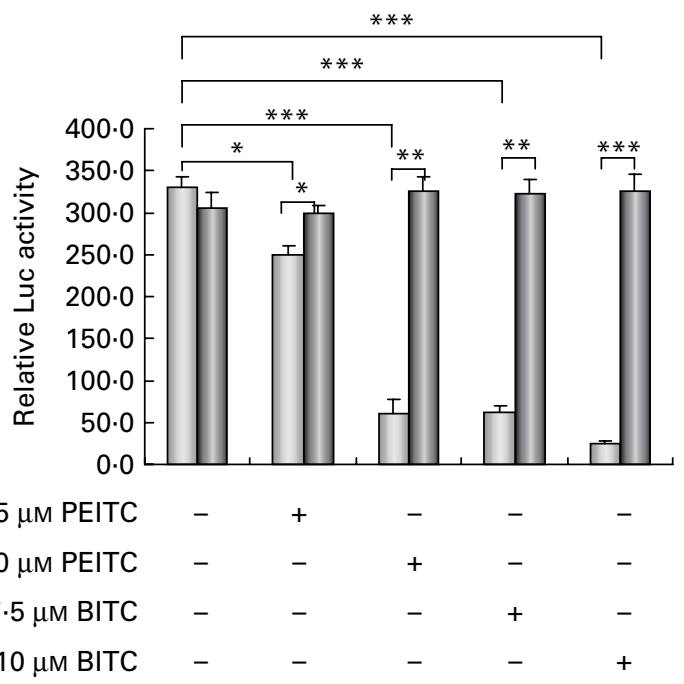

(b)

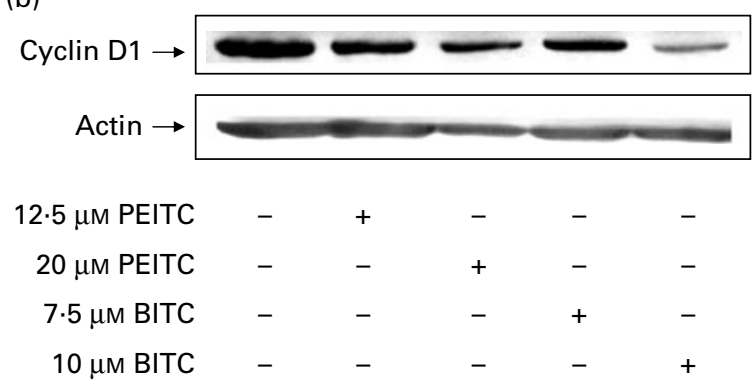

Fig. 5. Effect of isothiocyanates on activator protein 1 (AP-1) transcriptional activation. (a) L9981 cells were transfected with pAP-1, and pRL-SV40 served as an internal control. Then the cells were treated with $7.5-20 \mu \mathrm{M}$ of benzyl isothiocyanate (BITC) or phenethyl isothiocyanate (PEITC) for $18 \mathrm{~h}$. For $\mathrm{N}$-acetyl cysteine (NAC) protection, cells were pretreated with NAC $(1 \mathrm{~mm})$ for $1 \mathrm{~h}$. AP-1 transcriptional activation was detected by luciferase reporter assay. $\square,-N A C ; \square,+N A C$. (b) L9981 cells were treated with $7.5-20 \mu \mathrm{M}$ of BITC or PEITC for $24 \mathrm{~h}$. Samples were harvested, then lysed and subjected to SDS-PAGE, transferred to membrane and blotted with the antibody against cyclin D1. Values are means, with standard deviations of three independent experiments represented by vertical bars. Mean values were significantly different: ${ }^{\star} P<0.05,{ }^{* \star} P<0.01$ and ${ }^{* * *} P<0.001$. Similar results were obtained in three independent experiments. 
respond to extracellular stimuli and regulate various cellular activities, such as gene expression, mitosis, differentiation, proliferation and cell survival/apoptosis. To understand the role of the MAPK pathway in apoptosis induced by BITC and PEITC in L9981 cells, the activation/phosphorylation of MAPK was investigated by Western blotting. As shown in Fig. 4, $24 \mathrm{~h}$ treatment of L9981 cells by PEITC resulted in a strong and dose-dependent activation of three MAPK (JNK, ERK1/2 and p38). It was found that $20 \mu \mathrm{M}$ of PEITC were more potent than $12.5 \mu \mathrm{M}$ of PEITC. BITC also activated JNK, ERK1/2 and p38; however, it was not in a linear dose-dependent manner. It was found that $7.5 \mu \mathrm{M}$ of BITC were more potent than $10 \mu \mathrm{M}$ of BITC. Pretreatment with $1 \mathrm{~mm}$ of NAC attenuated the activation of MAPK by both BITC and PEITC.

\section{Benzyl isothiocyanate and phenethyl isothiocyanate repressed activator protein 1 transcriptional activation}

Following the findings that isothiocyanates activated MAPK, we further examined their effects on the transcriptional factor AP-1, a downstream target of MAPK. AP-1 controls a number of cellular processes including differentiation, proliferation and apoptosis. In the present study, we investigated the effects of BITC and PEITC on AP-1 transcriptional activation, by luciferase reporter assay. As shown in Fig. 5(a), both BITC and PEITC inhibited the transcriptional activation of AP-1 in a dose-dependent manner. After treatments for $18 \mathrm{~h}, 12.5$ and $20 \mu \mathrm{M}$ of PEITC significantly inhibited the transcriptional activity of AP-1 to $75.9 \%(P<0.05)$ and $18.2 \%$ $(P<0 \cdot 001)$ of control, respectively. Similar to PEITC, 7.5 and $10 \mu \mathrm{M}$ of BITC significantly inhibited the transcriptional activity of $\mathrm{AP}-1$ to $18.8 \%(P<0 \cdot 001)$ and $7 \cdot 4 \%(P<0 \cdot 001)$ of control, respectively. We further investigated the protective effect of antioxidant NAC. Pretreatment with antioxidant NAC (1 mM) for $1 \mathrm{~h}$ attenuated the inhibitory effect of BITC and PEITC on AP-1 transcriptional activation $(P<0.05)$.

To examine the effects of isothiocyanates on AP-1-regulated genes, we next detected the expression level of cyclin D1 in L9981 cells after treatments with BITC and PEITC. Cyclin D1 has been known to be an endogenous gene that is under the control of AP-1 and plays an important role in cell proliferation. Western blotting results showed that cyclin D1 levels were reduced by both BITC and PEITC, in a dose-dependent manner (Fig. 5(b)). This was well correlated with AP-1 transactivation result. (a)

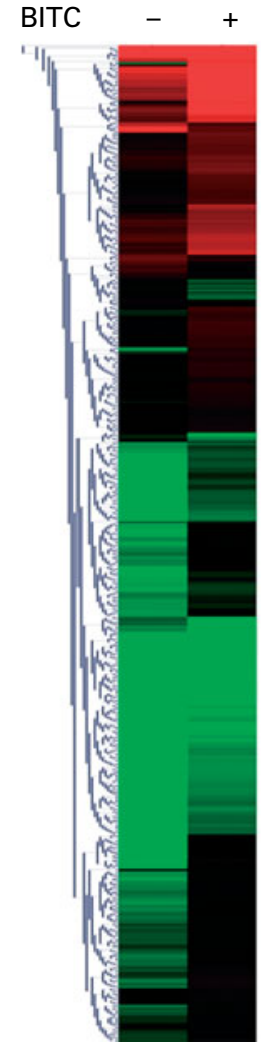

$0 \cdot 0$

(b) BITC

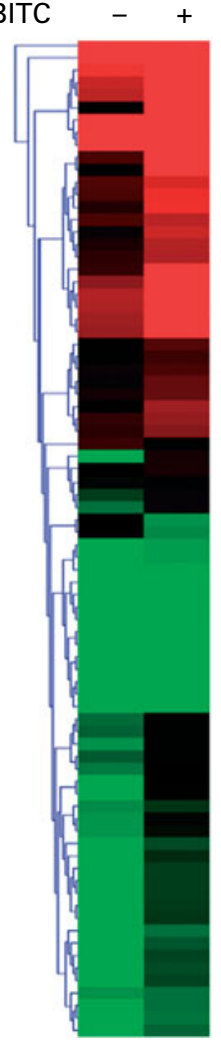

(c)

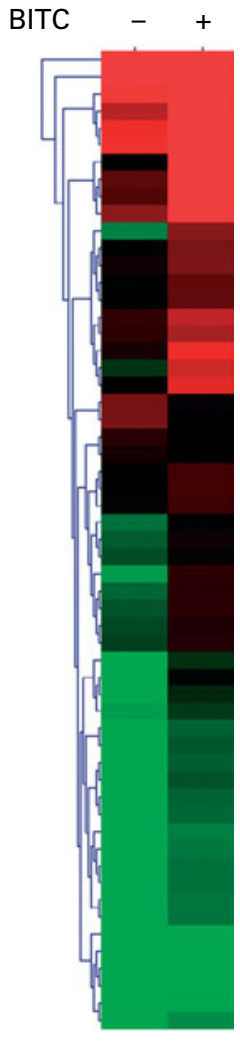

Fig. 6. Effect of benzyl isothiocyanate (BITC) on the gene expression profile. L9981 cells were treated with $20 \mu \mathrm{M}$ of BITC for $24 \mathrm{~h}$. Sample preparation and microarray analysis were described in Materials and Methods. (a) Hierarchical clustering of total genes differentially expressed. (b) Hierarchical clustering of apoptosisrelated genes differentially expressed. (c) Hierarchical clustering of cell cycle-related genes differentially expressed. 
Table 2. Apoptosis-related genes modulated by benzyl isothiocyanate

\begin{tabular}{|c|c|c|c|}
\hline GenBank & Symbol & $\begin{array}{l}\text { B20 v. control } \\
\text { signal log ratio }\end{array}$ & Name \\
\hline BG528420 & SOX4 & 4.5 & SRY (sex determining region Y)-box 4 \\
\hline NM_014061 & MAGEH1 & 3.9 & Melanoma antigen family $\mathrm{H}, 1$ \\
\hline NM_005346 & HSPA1B & $3 \cdot 6$ & Heat shock $70 \mathrm{kDa}$ protein $1 \mathrm{~B}$ \\
\hline BG283584 & SCIN & $3 \cdot 6$ & Scinderin \\
\hline AF220532 & NR2E1 & 3.3 & Nuclear receptor subfamily 2 , group $\mathrm{E}$, member 1 \\
\hline AF007162 & CRYAB & $3 \cdot 2$ & Crystallin, $\alpha$ B \\
\hline NM_005794 & DHRS2 & $3 \cdot 0$ & Dehydrogenase/reductase (SDR family) member 2 \\
\hline NM_015675 & GADD45B & $2 \cdot 8$ & Growth arrest and DNA-damage-inducible, beta \\
\hline NM_003901 & SGPL1 & $2 \cdot 8$ & Sphingosine-1-phosphate lyase 1 \\
\hline NM_005345 & HSPA1A & $2 \cdot 7$ & Heat shock $70 \mathrm{kDa}$ protein $1 \mathrm{~A}$ \\
\hline AL530331 & MEF2D & $2 \cdot 6$ & Myocyte enhancer factor 2D \\
\hline M25915 & CLU & $2 \cdot 3$ & Clusterin \\
\hline BC003637 & DDIT3 & $2 \cdot 3$ & DNA-damage-inducible transcript 3 \\
\hline L01639 & CXCR4 & $2 \cdot 2$ & Chemokine (C-X-C motif) receptor 4 \\
\hline NM_002133 & HMOX1 & $2 \cdot 2$ & Haeme oxygenase (decycling) 1 \\
\hline AA812232 & TXNIP & $2 \cdot 2$ & Thioredoxin interacting protein \\
\hline NM_000565 & IL6R & $2 \cdot 1$ & IL 6 receptor \\
\hline AW341649 & TP53INP1 & $2 \cdot 1$ & Tumour protein p53 inducible nuclear protein 1 \\
\hline BF447037 & JMY & 1.9 & Junction-mediating and regulatory protein \\
\hline NM_003900 & SQSTM1 & 1.9 & Sequestosome 1 \\
\hline NM_014330 & PPP1R15A & 1.8 & Protein phosphatase 1 , regulatory (inhibitor) subunit 15A \\
\hline NM_003811 & TNFSF9 & 1.8 & TNF (ligand) superfamily, member 9 \\
\hline NM_001124 & ADM & $1 \cdot 7$ & Adrenomedullin \\
\hline NM_004049 & BCL2A1 & 1.7 & BCL2-related protein A1 \\
\hline Al738896 & TNFAIP3 & 1.6 & TNF, $\alpha$-induced protein 3 \\
\hline Al091372 & AXUD1 & 1.5 & AXIN1 up-regulated 1 \\
\hline NM_003592 & CUL1 & 1.5 & Cullin 1 \\
\hline NM_019058 & DDIT4 & 1.5 & DNA-damage-inducible transcript 4 \\
\hline AF021233 & TNFRSF10D & 1.5 & TNF receptor superfamily, member $10 \mathrm{~d}$, decoy with truncated death domain \\
\hline BC002704 & STAT1 & 1.4 & Signal transducer and activator of transcription $1,91 \mathrm{kDa}$ \\
\hline NM_004281 & BAG3 & 1.3 & BCL2-associated athanogene 3 \\
\hline NM_001706 & BCL6 & 1.3 & B-cell CLL/lymphoma 6 (zinc finger protein 51) \\
\hline AL535380 & BTG1 & $1 \cdot 3$ & B-cell translocation gene 1, anti-proliferative \\
\hline AF356193 & CARD6 & 1.3 & Caspase recruitment domain family, member 6 \\
\hline AL564683 & CEBPB & $1 \cdot 3$ & CCAAT/enhancer binding protein (C/EBP), beta \\
\hline NM_003897 & IER3 & 1.3 & Immediate early response 3 \\
\hline NM_014456 & PDCD4 & $1 \cdot 3$ & Programmed cell death 4 (neoplastic transformation inhibitor) \\
\hline NM_013232 & PDCD6 & $1 \cdot 3$ & Programmed cell death 6 \\
\hline NM_012429 & SEC14L2 & 1.3 & SEC14-like 2 (S. cerevisiae) \\
\hline AB002438 & SEMA6A & 1.3 & Sema domain, transmembrane domain (TM), and cytoplasmic domain, (semaphorin) 6A \\
\hline AF322916 & UACA & 1.3 & Uveal autoantigen with coiled-coil domains and ankyrin repeats \\
\hline Al765327 & DCUN1D3 & $1 \cdot 2$ & DCN1, defective in cullin neddylation 1 , domain containing 3 (S. cerevisiae) \\
\hline NM_004417 & DUSP1 & $1 \cdot 2$ & Dual specificity phosphatase 1 \\
\hline NM_018063 & HELLS & 1.2 & Helicase, lymphoid-specific \\
\hline Al935096 & NR4A2 & $1 \cdot 2$ & Nuclear receptor subfamily 4 , group A, member 2 \\
\hline Al812030 & THBS1 & $1 \cdot 2$ & Thrombospondin 1 \\
\hline NM_001673 & ASNS & $1 \cdot 1$ & Asparagine synthetase \\
\hline NM_000389 & CDKN1A & $1 \cdot 1$ & Cyclin-dependent kinase inhibitor 1A (p21, Cip1) \\
\hline NM_015973 & GAL & $1 \cdot 1$ & Galanin \\
\hline BG491844 & JUN & $1 \cdot 1$ & Jun oncogene \\
\hline NM_000248 & MITF & $1 \cdot 1$ & Microphthalmia-associated transcription factor \\
\hline NM_002448 & MSX1 & $1 \cdot 1$ & Msh homeobox 1 \\
\hline AF310105 & NLRP1 & $1 \cdot 1$ & NLR family, pyrin domain containing 1 \\
\hline NM_002135 & NR4A1 & $1 \cdot 1$ & Nuclear receptor subfamily 4 , group A, member 1 \\
\hline NM_002656 & PLAGL1 & $1 \cdot 1$ & Pleiomorphic adenoma gene-like 1 \\
\hline Al806984 & RARA & $1 \cdot 1$ & Retinoic acid receptor, $\alpha$ \\
\hline AW007163 & TAOK2 & $1 \cdot 1$ & TAO kinase 2 \\
\hline NM_016653 & ZAK & $1 \cdot 1$ & Sterile $\alpha$ motif and leucine zipper containing kinase AZK \\
\hline NM_006538 & BCL2L11 & 1.0 & BCL2-like 11 (apoptosis facilitator) \\
\hline NM_003723 & CASP4 & 1.0 & Caspase Caspase-4, apoptosis-related cysteine peptidase \\
\hline NM_006079 & CITED2 & $1 \cdot 0$ & Cbp/p300-interacting transactivator, with Glu/Asp-rich carboxy-terminal domain, 2 \\
\hline NM_018693 & FBXO11 & 1.0 & F-box protein 11 \\
\hline NM_001453 & FOXC1 & 1.0 & Forkhead box C1 \\
\hline N25732 & $\mathrm{FOXO} 3$ & 1.0 & Forkhead box $\mathrm{O} 3$ \\
\hline NM_001924 & GADD45A & 1.0 & Growth arrest and DNA-damage-inducible, $\alpha$ \\
\hline D87811 & GATA6 & 1.0 & GATA binding protein 6 \\
\hline BE732345 & NBPF10 & 1.0 & Neuroblastoma breakpoint family, member 10 \\
\hline NM_007184 & $\mathrm{NISCH}$ & 1.0 & Nischarin \\
\hline
\end{tabular}


Table 2. Continued

\begin{tabular}{llcl}
\hline GenBank & Symbol & $\begin{array}{c}\text { B20 v. control } \\
\text { signal log ratio }\end{array}$ & Name \\
\hline NM_002737 & PRKCA & 1.0 & Protein kinase C, $\alpha$ \\
NM_018434 & RNF130 & 1.0 & Ring finger protein 130 \\
NM_022157 & RRAGC & 1.0 & Ras-related GTP binding C \\
BC000329 & SFN & 1.0 & Stratifin \\
NM_005627 & SGK & 1.0 & Serum/glucocorticoid regulated kinase \\
AB040927 & SH3RF1 & 1.0 & SH3 domain containing ring finger 1 \\
AA844682 & SYVN1 & 1.0 & Synovial apoptosis inhibitor 1, synoviolin \\
NM_006024 & TAX1BP1 & 1.0 & Tax1 (human T-cell leukaemia virus type I) binding protein 1 \\
NM_013438 & UBQLN1 & 1.0 & Ubiquilin 1 \\
W37431 & MAPK9 & -1.0 & Mitogen-activated protein kinase 9 \\
BE742268 & SORT1 & -1.3 & Sortilin 1 \\
U02632 & KCNMA1 & -1.5 & Potassium large conductance calcium-activated channel, subfamily M, $\alpha$ member 1 \\
\hline
\end{tabular}

\section{Effect of benzyl isothiocyanate on gene expression profile}

To further detail the global gene transcriptional changes induced by isothiocyanate and explore the potential targeted genes, high-density microarrays were performed. As BITC was more effective than PEITC, we examined L9981 cells treated with $10 \mu \mathrm{m}$ of BITC for $24 \mathrm{~h}$ using Affymetrix GeneChip. After a data normalisation procedure, a total of 1305 genes were found to be differentially expressed. Among these genes, 1166 genes were up-regulated and 139 genes were down-regulated.

Based on the present findings that iosthiocyanates induced L9981 cell apoptosis and cell cycle arrest, we further evaluated the potential targeted genes related to apoptosis and cell cycle in array data. For apoptosis-related genes, a total of eighty genes were regulated by BITC; seventy-seven of them were up-regulated and three of them were down-regulated. For genes involved in the cell cycle, fifty-seven genes were regulated by BITC; fifty-two of them were up-regulated and five of them were down-regulated. Fig. 6 illustrates the hierarchical clustering analysis of differentially expressed genes. Regulated genes are listed in Tables 2 and 3. Expression profiles of selected genes PDCD4, CCNG2 and GADD45A were then confirmed using real-time PCR. Using RNA isolated from a different experiment, real-time PCR analysis generated data highly similar to that derived from the microarray (Figs. 6 and 7, Table 3).

\section{Discussion}

Metastasis is the most common cause of death in cancer patients. It was found that $90 \%$ of lung cancer patients die of metastasis ${ }^{(22)}$. New strategies to prevent and treat cancer metastasis are urgently needed. Therefore, research and development of novel anti-metastatic drugs is one of the most active fields in cancer research. Recent studies ${ }^{(16-18)}$ have shown that isothiocyanates effectively suppressed metastasis potential of tumour cells; however, the mechanism is not fully understood. There are several possible ways to suppress tumour cell metastasis: for example, to reverse the metastasis potential by regulating metastasis-related genes and pathways, to inhibit metastatic cell growth by inducing cell cycle arrest or to eliminate the metastatic cells by inducing apoptosis. Our previous study demonstrated that BITC and PEITC suppressed metastasis potential of highly metastatic human lung cancer the L9981 cells by the modulation of metastasis-related matrix metalloproteinases-2, Twist and $\beta$-catenin expression, inhibition of the Akt/NF- $\mathrm{B}$ pathway and induction of oxidative stress $^{(19)}$. In the present study, we explored other possible ways to suppress NSCLC cell metastasis.

We first examined the effect of BITC $(7 \cdot 5$ and $10 \mu \mathrm{m})$ and PEITC (12.5 and $20 \mu \mathrm{m})$ on cell migration and invasion by Wound Healing Assay and Cell Invasion Assay. Cell migration and invasion were more significantly reduced than BITC $(5 \mu \mathrm{M})$ and PEITC $(10 \mu \mathrm{M})$ in our previous study ${ }^{(19)}$ (data not shown).

The induction of apoptosis by isothiocyanates was first documented by Yu et $a l .{ }^{(23)}$. Their study showed that PEITC and other structurally related isothiocyanates, phenylmethyl isothiocyanate, phenylbutyl isothiocyanate and phenylhexyl isothiocyanate, induced HeLa cell apoptosis in a time and dose-dependent manner. Since then, the apoptosis induction effect of isothiocyanates has been studied in several types of cancer cells. The mechanism is not fully understood, although there is evidence showing that apoptosis is mediated by caspase- 3 and -8 activation, poly-(ADP-ribose) polymerase and Bid cleavage, JNK and ERK1/2 activation ${ }^{(6,7,24)}$. However, there is no report on their apoptosis induction effect in metastatic lung cancer cells. The present study demonstrated, for the first time, that BITC and PEITC induced highly metastatic human lung cancer cell apoptosis in a dose-dependent manner. Caspase- 3 plays a central role in the execution phase of cell apoptosis. It responds to caspase-8, -9, -10, and cleaves and activates caspase-6, -7, -9. In the present study, caspase-3 was activated in L9981 cells. This is consistent with our previous findings in human leukaemia cells, in which HL60 and ML-1 cells induced apoptosis by PEITC and allyl isothiocyanate via caspase- 3 and -8 activation ${ }^{(7)}$.

Isothiocyanates also inhibit cell cycle progress. The cell cycle may be arrested at the $G_{1}$ phase or $G_{2} / M$ phase, depending on the cell types ${ }^{(5)}$. Our data showed that BITC and PEITC delayed highly metastastic human lung cancer cell cycle progress and caused $\mathrm{G}_{2} / \mathrm{M}$ phase arrest. Although the exact molecular mechanisms responsible for cell cycle arrest are 
Table 3. Cell cycle-related genes modulated by benzyl isothiocyanate

\begin{tabular}{|c|c|c|c|}
\hline GenBank & Symbol & $\begin{array}{l}\text { B20 v. control } \\
\text { signal log ratio }\end{array}$ & Name \\
\hline NM_000499 & CYP1A1 & 4.5 & Cytochrome P450, family 1 , subfamily A, polypeptide 1 \\
\hline NM_000584 & IL8 & $3 \cdot 8$ & IL 8 \\
\hline AW157094 & ID4 & 3.0 & Inhibitor of DNA binding 4, dominant negative helix-loop-helix protein \\
\hline NM_015675 & GADD45B & $2 \cdot 8$ & Growth arrest and DNA-damage-inducible, beta \\
\hline NM_002923 & RGS2 & 2.5 & Regulator of G-protein signalling 2, $24 \mathrm{kDa}$ \\
\hline BF131886 & SESN2 & 2.5 & Sestrin 2 \\
\hline BC003637 & DDIT3 & $2 \cdot 3$ & DNA-damage-inducible transcript 3 \\
\hline AA812232 & TXNIP & $2 \cdot 2$ & Thioredoxin interacting protein \\
\hline AW341649 & TP53INP1 & $2 \cdot 1$ & Tumour protein p53 inducible nuclear protein 1 \\
\hline BF447037 & JMY & 1.9 & Junction-mediating and regulatory protein \\
\hline AW134535 & CCNG2 & $1 \cdot 8$ & Cyclin G2 \\
\hline NM_014330 & PPP1R15A & 1.8 & Protein phosphatase 1 , regulatory (inhibitor) subunit $15 \mathrm{~A}$ \\
\hline R78668 & CDKN1C & 1.6 & Cyclin-dependent kinase inhibitor 1C (p57, Kip2) \\
\hline NM_003592 & CUL1 & 1.5 & Cullin 1 \\
\hline Z25431 & NEK1 & 1.4 & NIMA (never in mitosis gene a)-related kinase 1 \\
\hline NM_005652 & TERF2 & 1.4 & Telomeric repeat binding factor 2 \\
\hline NM_001706 & BCL6 & $1 \cdot 3$ & B-cell CLL/lymphoma 6 (zinc finger protein 51 ) \\
\hline NM_001240 & CCNT1 & $1 \cdot 3$ & Cyclin T1 \\
\hline NM_002166 & ID2 & 1.3 & Inhibitor of DNA binding 2, dominant negative helix-loop-helix protein \\
\hline NM_002229 & JUNB & $1 \cdot 3$ & Jun B proto-oncogene \\
\hline NM_014456 & PDCD4 & 1.3 & Programmed cell death 4 (neoplastic transformation inhibitor) \\
\hline NM_012237 & SIRT2 & $1 \cdot 3$ & Sirtuin (silent mating type information regulation 2 homologue) 2 (S. cerevisiae) \\
\hline AA824369 & BTRC & $1 \cdot 2$ & Beta-transducin repeat containing \\
\hline Al765327 & DCUN1D3 & $1 \cdot 2$ & DCN1, defective in cullin neddylation 1 , domain containing 3 (S. cerevisiae) \\
\hline NM_004417 & DUSP1 & $1 \cdot 2$ & Dual specificity phosphatase 1 \\
\hline NM_012257 & HBP1 & $1 \cdot 2$ & HMG-box transcription factor 1 \\
\hline NM_018063 & HELLS & $1 \cdot 2$ & Helicase, lymphoid-specific \\
\hline NM_002811 & PSMD7 & $1 \cdot 2$ & Proteasome (prosome, macropain) $26 \mathrm{~S}$ subunit, non-atpase, 7 \\
\hline NM_007182 & RASSF1 & $1 \cdot 2$ & Ras association (ralgds/AF-6) domain family 1 \\
\hline NM_005667 & RNF103 & $1 \cdot 2$ & Ring finger protein 103 \\
\hline N48361 & SENP5 & $1 \cdot 2$ & SUMO1/sentrin specific peptidase 5 \\
\hline Al812030 & THBS1 & $1 \cdot 2$ & Thrombospondin 1 \\
\hline NM_022117 & TSPYL2 & $1 \cdot 2$ & TSPY-like 2 \\
\hline NM_001673 & ASNS & $1 \cdot 1$ & Asparagine synthetase \\
\hline NM_000389 & CDKN1A & $1 \cdot 1$ & Cyclin-dependent kinase inhibitor $1 \mathrm{~A}(\mathrm{p} 21, \mathrm{Cip} 1)$ \\
\hline AA555096 & CYLD & $1 \cdot 1$ & Cylindromatosis (turban tumour syndrome) \\
\hline BG491844 & JUN & $1 \cdot 1$ & Jun oncogene \\
\hline NM_006559 & KHDRBS1 & $1 \cdot 1$ & $\mathrm{KH}$ domain containing, RNA binding, signal transduction associated 1 \\
\hline NM_003550 & MAD1L1 & $1 \cdot 1$ & MAD1 mitotic arrest deficient-like 1 (yeast) \\
\hline BE256969 & PAFAH1B1 & $1 \cdot 1$ & Platelet-activating factor acetylhydrolase, isoform lb, $\alpha$ subunit $45 \mathrm{kDa}$ \\
\hline NM_002656 & PLAGL1 & $1 \cdot 1$ & Pleiomorphic adenoma gene-like 1 \\
\hline Al806984 & RARA & $1 \cdot 1$ & Retinoic acid receptor, $\alpha$ \\
\hline NM_016653 & ZAK & $1 \cdot 1$ & Sterile $\alpha$ motif and leucine zipper containing kinase AZK \\
\hline NM_006079 & CITED2 & 1.0 & Cbp/p300-interacting transactivator, with Glu/Asp-rich carboxy-terminal domain, 2 \\
\hline BF211488 & ESCO1 & 1.0 & Establishment of cohesion 1 homologue 1 (S. cerevisiae) \\
\hline NM_001453 & FOXC1 & 1.0 & Forkhead box C1 \\
\hline NM_001924 & GADD45A & $1 \cdot 0$ & Growth arrest and DNA-damage-inducible, $\alpha$ \\
\hline BE732345 & NBPF10 & 1.0 & Neuroblastoma breakpoint family, member 10 \\
\hline NM_015384 & NIPBL & $1 \cdot 0$ & Nipped-B homologue (Drosophila) \\
\hline BC000329 & SFN & 1.0 & Stratifin \\
\hline BG286461 & TBRG1 & 1.0 & Transforming growth factor beta regulator 1 \\
\hline NM_017853 & TXNL4B & 1.0 & Thioredoxin-like 4B \\
\hline NM_022782 & MPHOSPH9 & $-1 \cdot 0$ & M-phase phosphoprotein 9 \\
\hline AW003362 & NASP & -1.0 & Nuclear autoantigenic sperm protein (histone-binding) \\
\hline BF215487 & PSMC2 & $-1 \cdot 1$ & Proteasome (prosome, macropain) 26S subunit, atpase, 2 \\
\hline BG105365 & SKP2 & -1.5 & S-phase kinase-associated protein 2 (p45) \\
\hline BF110993 & TPR & -1.6 & Translocated promoter region (to activated MET oncogene) \\
\hline
\end{tabular}

still mostly unknown, some potential targets of isothiocyanates have been postulated. Cyclins are a family of proteins that control the progression of cells through the cell cycle by activating cyclin-dependent kinase enzymes, such as cdc 2 and cdk2. Activation of cdc2 is controlled at several steps including cyclin B1 binding. The cdc2-cyclin B1 kinase activity is pivotal in regulating $\mathrm{G}_{2} / \mathrm{M}$ transition. In human prostate cancer cells, AITC-induced $\mathrm{G}_{2} / \mathrm{M}$ phase arrest was accompanied by a significant decrease in the cyclin B1 level $^{(25)}$. The down-regulation of $\mathrm{cdk} 1$ and $\mathrm{cdc} 25 \mathrm{~B}$ was also observed in the AITC-induced $\mathrm{G}_{2} / \mathrm{M}$-arrested cells. Miyoshi et al. ${ }^{(26,27)}$ reported that BITC inhibited human leukaemia cell $\mathrm{G}_{2} / \mathrm{M}$ progression by up-regulating the expression of the $\mathrm{G}_{2} / \mathrm{M}$ cell cycle arrest-regulating genes including p21 and inhibiting cyclin-dependent kinase activity by directly binding to $\mathrm{CDK} /$ cyclin complexes including $\mathrm{Cdc} 2 /$ cyclin $\mathrm{B} 1$ kinase. 


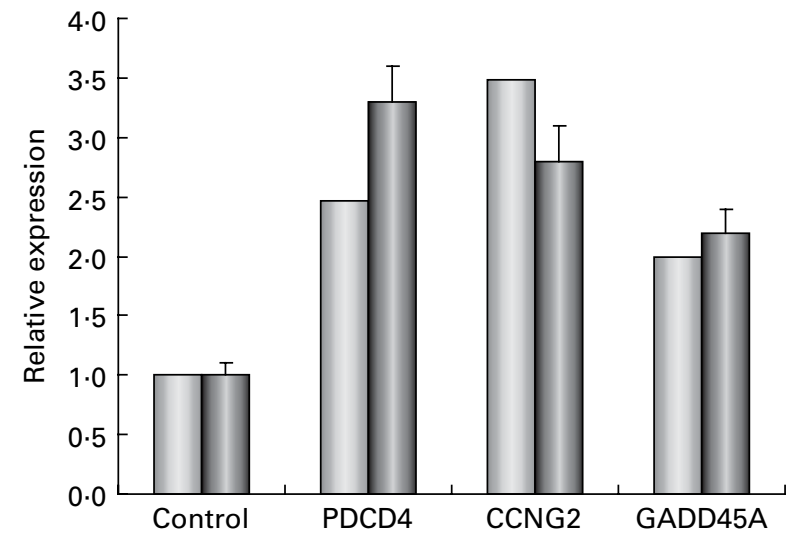

Fig. 7. Effect of benzyl isothiocyanate (BITC) on gene expression. The expression patterns observed using microarray analysis were confirmed with quantitative RT-PCR using programmed cell death 4 (PDCD4), cyclin G2 (CCNG2) and growth arrest and DNA damage-inducible $\alpha$ (GADD45A). L9981 cells were treated with BITC as described previously, and total RNA was harvested $24 \mathrm{~h}$ post-treatment. Relative expression levels for PDCD4, CCNG2 and GADD45A derived from array ( $\square$ ) and RT-PCR ( $\square$ ) were indicated.

We found that both BITC and PEITC reduced cyclin B1 expression in a dose-dependent manner in L9981 cells. Altogether, these findings suggested that cyclin $\mathrm{B} 1, \mathrm{cdk} 1$ and cdc25B may be targeted by isothiocyanates.

The present study also aimed at elucidating the underlying network of signalling events in the BITC- and PEITC-induced apoptosis of L9981 cells. MAPK are important mediators involved in the intracellular network of interacting proteins that transduce extracellular signals to intracellular responses. When the MAPK cascade is activated, signals lead to the activation of diverse molecules that regulate cell growth, survival and differentiation ${ }^{(28)}$. The present study showed that activations of JNK, ERK1/2 and p38 are involved in the induction of apoptosis by BITC and PEITC. Hu et al. ${ }^{(24)}$ reported that three MAPK (JNK, ERK1/2 and p38) were activated after PEITC treatment in colon adenocarcinoma HT-29 cells. However, in ovarian cancer cells OVCAR-3, PEITC suppressed the activation of ERK1/2 while simultaneously activating proapoptotic p38 and $\mathrm{JNK} 1 / 2^{(29)}$. This indicated that the role of ERK in isothiocyanate-induced apoptosis is controversial.

AP-1 is one of the transcription factors regulated by MAPK. $\mathrm{AP}-1$ regulates a wide range of cellular processes, including cell proliferation, death, survival and differentiation. AP-1 has been proposed to play important roles in carcinogenesis and cancer development ${ }^{(30,31)}$. Isothiocyanates activate AP-1 activity in prostate cancer cells ${ }^{(32)}$ and bladder cancer cells $^{(33)}$. Interestingly, $\mathrm{Xu}$ et al. reported that in colon cancer cells, a low concentration of PEITC and sulforaphane activates AP-1 activity, but at higher concentrations, they suppress AP-1 activity $^{(34)}$. Our data showed that BITC and PEITC suppressed AP-1 activity in highly metastatic lung cancer L9981 cells. These suggested that the effect of isothiocyanates on AP-1 activity may depend on the types and concentrations of isothiocyanates, as well as on the cell types.

Cyclin D1 is one of the genes under the control of AP-1. Cyclin D1 forms a complex with and functions as a regulatory subunit of CDK4 or CDK6, whose activity is required for cell cycle $\mathrm{G}_{1} / \mathrm{S}$ transition. Cell proliferation is regulated by cyclin $\mathrm{D} / \mathrm{CDK} 4 / 6$. Numerous studies show that isothiocyanates inhibit several types of cancer, including prostate cancer ${ }^{(32)}$, colon carcinoma $^{(35)}$, pancreatic carcinoma ${ }^{(36)}$, which is associated with the inhibition of cyclin D1 expression. Further studies show that these effects are mediated by MAPK, NF- $\mathrm{B}$ and STAT3 pathways. The present study demonstrated that BITC and PEITC inhibited cyclin D1 expression via the MAPK/AP-1 pathway.

ROS are essential for biological functions. ROS are involved in signalling cell growth and differentiation, regulating the activity of enzymes, mediating inflammation and eliminating pathogens and foreign particles. The generation of ROS is part of the mechanism by which most chemotherapeutic agents or ionising radiation kill tumour cells ${ }^{(37)}$. Isothiocyanates elevate ROS level in different types of cancer, such as leukaemia $^{(38)}$, breast cancer $^{(39)}$ and pancreatic cancer ${ }^{(40)}$ Recent work from our laboratory has shown that BITC and PEITC induce the generation of ROS in L9981 cells. To explore whether the induction of oxidative stress plays a role in the induction of apoptosis, we pre-treated L9981 cells with antioxidant NAC. Our data showed that NAC attenuated apoptosis induction, MAPK activation and AP-1 suppression by BITC and PEITC, suggesting that cell death signalling was triggered by oxidative stress.

The inhibitory effect of BITC and PEITC on highly metastatic lung cancer cells prompted us to perform further work aimed at identifying isothiocyanate-targeted genes related to apoptosis or cell cycle. For this, we performed microarray studies to define the gene expression profiles observed in L9981 cells in response to BITC treatment. A number of genes that seem to be regulated by BITC and have relevance to apoptosis and the cell cycle were identified by using such an approach. Among the apoptosis-related genes, TNF is well known in the regulation of a wide spectrum of biological processes including cell proliferation, differentiation, apoptosis, lipid metabolism and coagulation ${ }^{(41)}$. Programmed cell death 4 is a tumour suppressor and plays an important role in cell apoptosis ${ }^{(42)}$. Caspase- 4 is a member of the caspase family. This caspase is able to cleave and activate its own precursor protein as well as a caspase- 1 precursor. It promotes apoptosis when activated ${ }^{(43)}$. Our microarray data analysis also showed that a number of cell cycle-related genes were regulated by BITC. Growth arrest and DNA damage-inducible- $\alpha$ is up-regulated following stressful growth arrest conditions and treatment with DNA-damaging agents. It is closely related with cell cycle arrest in human liver carcinoma cells treated with fucoxanthin ${ }^{(44)}$. Another cell cycle-related gene is cyclin G2. Ectopic expression of cyclin G2 inhibits cyclin-dependent kinase 2 activity, Rb phosphorylation, cell cycle progression and cellular proliferation. A study showed that elevated cyclin G2 expression is associated with antihuman epidermal growth factor receptor 2 antibody-mediated inhibition of breast caner cell growth ${ }^{(45)}$

In summary, the present results showed that BITC and PEITC suppressed the metastasis potential of highly metastatic human lung cancer L9981 cells by the induction of apoptosis 
and cell cycle arrest. The MAPK pathway was involved in suppression and was the potential targeted pathway of isothiocyanates. Apoptosis and MAPK activation were blocked by antioxidant NAC, suggesting that cell death signalling was triggered by oxidative stress. Targeted genes related to apoptosis and the cell cycle were identified, and further work on the definition of new targeted signalling pathways and genes is warranted.

\section{Acknowledgements}

The present study was supported by the National Natural Science Foundation of China (30873035), Key Project of Tianjin Municipal Education Commission (ZD200714), Key Project of Tianjin Municipal Science and Technology Commission (10JCZDJC20800), and the Start-Up Fund of the Ministry of Education of China. K. X., X. W. and Q. Z. designed the study; H. Y., Y. Z., B. L., H. W. and Y. L. performed the experiments; K. X., X. W. and Q. Z. analysed the data and wrote the paper. The authors declare that there is no conflict of interest.

\section{References}

1. Ferlay J, Shin HR, Bray F, et al. (2010) Estimates of worldwide burden of cancer in 2008: GLOBOCAN 2008. Int J Cancer 127, 2893-2917.

2. Rudd RM, Gower NH, Spiro SG, et al. (2005) Gemcitabine plus carboplatin versus mitomycin, ifosfamide, and cisplatin in patients with stage IIIB or IV non-small-cell lung cancer: a phase III randomized study of the London Lung Cancer Group. J Clin Oncol 23, 142-153.

3. Martoni A, Marino A, Sperandi F, et al. (2005) Multicentre randomised phase III study comparing the same dose and schedule of cisplatin plus the same schedule of vinorelbine or gemcitabine in advanced non-small cell lung cancer. Eur J Cancer 41, 81-92.

4. Lam TK, Gallicchio L, Lindsley K, et al. (2009) Cruciferous vegetable consumption and lung cancer risk: a systematic review. Cancer Epidemiol Biomarkers Prev 18, 184-195.

5. Wu X, Zhou QH \& Xu K (2009) Are isothiocyanates potential anti-cancer drugs? Acta Pharmacol Sin 30, 501-512.

6. Xu K \& Thornalley PJ (2001) Signal transduction activated by the cancer chemopreventive isothiocyanates: cleavage of BID protein, tyrosine phosphorylation and activation of JNK. Br J Cancer 84, 670-673.

7. Xu K \& Thornalley PJ (2000) Studies on the mechanism of the inhibition of human leukaemia cell growth by dietary isothiocyanates and their cysteine adducts in vitro. Biochem Pharmacol 60, 221-231.

8. Gong A, He M, Krishna Vanaja D, et al. (2009) Phenethyl isothiocyanate inhibits STAT3 activation in prostate cancer cells. Mol Nutr Food Res 53, 878-886.

9. Kang L, Ding L \& Wang ZY (2009) Isothiocyanates repress estrogen receptor alpha expression in breast cancer cells. Oncol Rep 21, 185-192.

10. Mi L, Gan N, Cheema A, et al. (2009) Cancer preventive isothiocyanates induce selective degradation of cellular alpha- and beta-tubulins by proteasomes. J Biol Chem $\mathbf{2 8 4}$, 17039-17051.

11. Mukherjee S, Dey S, Bhattacharya RK, et al. (2009) Isothiocyanates sensitize the effect of chemotherapeutic drugs via modulation of protein kinase $\mathrm{C}$ and telomerase in cervical cancer cells. Mol Cell Biochem 330, 9-22.
12. Prawan A, Saw CL, Khor TO, et al. (2009) Anti-NF-kappaB and anti-inflammatory activities of synthetic isothiocyanates: effect of chemical structures and cellular signaling. Chem Biol Interact 179, 202-211.

13. Xiao D \& Singh SV (2007) Phenethyl isothiocyanate inhibits angiogenesis in vitro and ex vivo. Cancer Res $\mathbf{6 7}$, 2239-2246.

14. Thejass P \& Kuttan G (2007) Inhibition of endothelial cell differentiation and proinflammatory cytokine production during angiogenesis by allyl isothiocyanate and phenyl isothiocyanate. Integr Cancer Ther 6, 389-399.

15. Thejass P \& Kuttan G (2007) Allyl isothiocyanate (AITC) and phenyl isothiocyanate (PITC) inhibit tumour-specific angiogenesis by downregulating nitric oxide (NO) and tumour necrosis factor-alpha (TNF-alpha) production. Nitric Oxide 16, 247-257.

16. Hwang ES \& Lee HJ (2008) Benzyl isothiocyanate inhibits metalloproteinase-2/-9 expression by suppressing the mitogenactivated protein kinase in SK-Hep1 human hepatoma cells. Food Chem Toxicol 46, 2358-2364.

17. Lai KC, Huang AC, Hsu SC, et al. (2010) Benzyl isothiocyanate (BITC) inhibits migration and invasion of human colon cancer HT29 cells by inhibiting matrix metalloproteinase-2/-9 and urokinase plasminogen (uPA) through PKC and MAPK signaling pathway. J Agric Food Chem 58, 2935-2942.

18. Hunakova L, Sedlakova O, Cholujova D, et al. (2009) Modulation of markers associated with aggressive phenotype in MDA-MB-231 breast carcinoma cells by sulforaphane. Neoplasma 56, 548-556.

19. Wu X, Zhu Y, Yan H, et al. (2010) Isothiocyanates induce oxidative stress and suppress the metastasis potential of human non-small cell lung cancer cells. BMC Cancer 10, 269.

20. Zhou Q, Wang Y, Che G, et al. (2003) Establishment and their biological characteristics of clonal cell subpopulations (NL9980 and L9981) from a human lung large cell carcinoma cell line (WCQH29801). Chin J Lung Canc 6, 464-468.

21. Xu K, Guidez F, Glasow A, et al. (2005) Benzodithiophenes potentiate differentiation of acute promyelocytic leukemia cells by lowering the threshold for ligand-mediated corepressor/coactivator exchange with retinoic acid receptor alpha and enhancing changes in all-trans-retinoic acidregulated gene expression. Cancer Res 65, 7856-7865.

22. Gupta GP \& Massague J (2006) Cancer metastasis: building a framework. Cell 127, 679-695.

23. Yu R, Mandlekar S, Harvey KJ, et al. (1998) Chemopreventive isothiocyanates induce apoptosis and caspase-3-like protease activity. Cancer Res 58, 402-408.

24. Hu R, Kim BR, Chen C, et al. (2003) The roles of JNK and apoptotic signaling pathways in PEITC-mediated responses in human HT-29 colon adenocarcinoma cells. Carcinogenesis 24, 1361-1367.

25. Xiao D, Srivastava SK, Lew KL, et al. (2003) Allyl isothiocyanate, a constituent of cruciferous vegetables, inhibits proliferation of human prostate cancer cells by causing $\mathrm{G} 2 / \mathrm{M}$ arrest and inducing apoptosis. Carcinogenesis $\mathbf{2 4}$, 891-897.

26. Miyoshi N, Uchida K, Osawa T, et al. (2004) A link between benzyl isothiocyanate-induced cell cycle arrest and apoptosis: involvement of mitogen-activated protein kinases in the Bcl-2 phosphorylation. Cancer Res 64, 2134-2142.

27. Miyoshi N, Uchida K, Osawa T, et al. (2004) Benzyl isothiocyanate modifies expression of the G2/M arrest-related genes. Biofactors 21, 23-26. 
28. Inamdar GS, Madhunapantula SV \& Robertson GP (2010) Targeting the MAPK pathway in melanoma: why some approaches succeed and other fail. Biochem Pharmacol 80, 624-637.

29. Satyan KS, Swamy N, Dizon DS, et al. (2006) Phenethyl isothiocyanate (PEITC) inhibits growth of ovarian cancer cells by inducing apoptosis: role of caspase and MAPK activation. Gynecol Oncol 103, 261-270.

30. Shaulian E \& Karin M (2002) AP-1 as a regulator of cell life and death. Nat Cell Biol 4, E131-E136.

31. Oya M, Takayanagi A, Horiguchi A, et al. (2003) Increased nuclear factor-kappa B activation is related to the tumor development of renal cell carcinoma. Carcinogenesis $\mathbf{2 4}$, 377-384.

32. Xu C, Shen G, Yuan X, et al. (2006) ERK and JNK signaling pathways are involved in the regulation of activator protein 1 and cell death elicited by three isothiocyanates in human prostate cancer PC-3 cells. Carcinogenesis 27, 437-445.

33. Yao S, Zhang Y \& Li J (2006) c-jun/AP-1 activation does not affect the antiproliferative activity of phenethyl isothiocyanate, a cruciferous vegetable-derived cancer chemopreventive agent. Mol Carcinog 45, 605-612.

34. Jeong WS, Kim IW, Hu R, et al. (2004) Modulation of AP-1 by natural chemopreventive compounds in human colon HT-29 cancer cell line. Pharm Res 21, 649-660.

35. Shen G, Xu C, Chen C, et al. (2006) p53-independent G1 cell cycle arrest of human colon carcinoma cells HT-29 by sulforaphane is associated with induction of p21CIP1 and inhibition of expression of cyclin D1. Cancer Chemother Pharmacol 57, 317-327.

36. Batra S, Sahu RP, Kandala PK, et al. (2010) Benzyl isothiocyanate-mediated inhibition of histone deacetylase leads to NF-kappaB turnoff in human pancreatic carcinoma cells. Mol Cancer Ther 9, 1596-1608.

37. Sun Y \& Rigas B (2008) The thioredoxin system mediates redox-induced cell death in human colon cancer cells: implications for the mechanism of action of anticancer agents. Cancer Res 68, 8269-8277.

38. Trachootham D, Zhang H, Zhang W, et al. (2008) Effective elimination of fludarabine-resistant CLL cells by PEITC through a redox-mediated mechanism. Blood 112, 1912-1922.

39. Xiao D, Powolny AA \& Singh SV (2008) Benzyl isothiocyanate targets mitochondrial respiratory chain to trigger reactive oxygen species-dependent apoptosis in human breast cancer cells. J Biol Chem 283, 30151-30163

40. Sahu RP, Zhang R, Batra S, et al. (2009) Benzyl isothiocyanatemediated generation of reactive oxygen species causes cell cycle arrest and induces apoptosis via activation of MAPK in human pancreatic cancer cells. Carcinogenesis 30 , $1744-1753$.

41. Faustman D \& Davis M (2010) TNF receptor 2 pathway: drug target for autoimmune diseases. Nat Rev Drug Discov 9, 482-493.

42. Sheedy FJ, Palsson-McDermott E, Hennessy EJ, et al. (2010) Negative regulation of TLR4 via targeting of the proinflammatory tumor suppressor PDCD 4 by the microRNA miR-21. Nat Immunol 11, 141-147.

43. King FW, Fong S, Griffin C, et al. (2009) Timosaponin AIII is preferentially cytotoxic to tumor cells through inhibition of mTOR and induction of ER stress. PLoS One 4, e 7283.

44. Satomi Y \& Nishino H (2009) Implication of mitogenactivated protein kinase in the induction of G1 cell cycle arrest and gadd 45 expression by the carotenoid fucoxanthin in human cancer cells. Biochim Biophys Acta 1790, $260-266$.

45. Le XF, Arachchige-Don AS, Mao W, et al. (2007) Roles of human epidermal growth factor receptor 2, c-jun NH2-terminal kinase, phosphoinositide 3-kinase, and p70 S6 kinase pathways in regulation of cyclin G2 expression in human breast cancer cells. Mol Cancer Ther 6, 2843-2857. 